\title{
Robar el paraíso. Indios, viruela y bautismo en Argentina (1870-1884)
}

\section{Maria Silvia Di Liscia'}

"Estos indios se mueren como han vivido. En la Pampa se llevaban ganado, aquí en pocos días se roban el cielo ¡Bendito sea Dios y vuestra excelencia!"”2. El comentario ingenuo del padre Birot, escrito en la correspondencia dirigida al arzobispo Aneiros desde el lazareto de la isla-penal Martín García, sintetiza en parte la concepción católica sobre la tarea misional en relación con los nativos de la Pampa y Patagonia. Los malones, incursiones indias Ilevadas a cabo durante décadas en la frontera para capturar ganado y cautivos, eran metafóricamente identificados con la desaparición de indígenas que, bautizados, irían a formar parte de las huestes cristianas, apropiandose del edén y la salvación. Por otra parte, las muertes indígenas también fueron objeto de reflexión entre políticos, militares y sobre todo, médicos, quienes trataron de justificar las terribles consecuencias de la viruela entre la población nativa, despojándose a su vez de responsabilidad frente a ese exterminio étnico indirecto.

1-F.C. Humanas, U. Nacional de La Pampa-I.U. Ortega y Gasset, U. Complutense.

Este artículo es parte de la Tesis Doctoral Itinerarios curativos. Saberes, prácticas y terapias médicas indígenas, populares y científicas (Región Pampeana, 1750-1910), realizada en el Instituto U. Ortega y Gasset (U. Complutense). Agradezco los comentarios y sugerencias de Manuel Gutiérrez Estévez y Ricardo González Leandri a una versión anterior de este trabajo.

2-COPELLO, S. 1945: 168. El autor realizó una exhaustiva recopilación del Archivo de la Secretaría del Arzobispado de Buenos Aires entre 1872 y 1880. 
El objetivo de este artículo es el análisis de los discursos y la acción religiosa y laica en relación a los indígenas y las epidemias de viruela entre 1870 y 1884 , haciendo hincapié en el momento en que se produjo la Campaña al Desierto. Se trata de un tema poco estudiado, que permitiría aclarar las complejas relaciones entre diferentes agentes sociales en relación con la integración (problemática) de la población nativa al conjunto nacional. Se examinan en primer lugar las distintas posturas, en el orden científico-ideológico, respecto a la influencia diferencial de la viruela entre los indígenas pampeanos y en segundo lugar, la tarea específica de la Iglesia y los conflictos frente al orden estatal reflejados en el tratamiento de los nativos durante una epidemia de viruela.

Desde la conquista hispánica, indios y blancos habían mantenido en la Región Pampeana (Argentina) intercambios comerciales y diplomáticos en alternancia con conflictos y ataques bélicos, provocados sobre todo por la competencia de recursos ganaderos. En 1850, la organización del Estado implicó una transformación importante en la "cuestión indígena", resuelta finalmente en los años '80 durante la presidencia de Julio A. Roca, promotor de la incorporación de la Pampa y la Patagonia y, consecuentemente, del exterminio étnico, que formaba parte de la ideología positivista de la élite nacional decimonónica ${ }^{3}$.

En el Primer Censo, realizado en 1869 durante la presidencia de Sarmiento, se registraron 93.138 indígenas, considerados como colectivo no diferenciado con el fin de obtener una evaluación del número de "lanzas", es decir, de enemigos en una contienda bélica. En el Segundo Censo, realizado en 1895, los indígenas habían descendido a 30.000 personas y en el Tercer Censo de 1914, a 18.425 , más unas 20.000 personas sin registrar. En el Segundo y Tercer Censo, una vez producida la Campaña al Desierto, la población que estaba en los territorios conquistados fue subsumida bajo la consideración de "argentinos", sin otras connotaciones étnicas. Los funcionarios encargados del censo explicaron la reducción del número de indígenas por su asimilación al conjunto nacional, sin examinar adecuadamente la influencia de la mortalidad producida por la campaña militar 4 .

Si se considera sobre todo este último factor, puesto que a partir de ese momento se inicia el descenso acelerado de la población indígena argentina, se debe tener en cuenta que la expedición estuvo relacionada con el exterminio de diferente manera. En primer lugar, por la conquista militar en sí misma, que

3-Sobre caracterizaciones generales de las poblaciones indígenas de la Región Pampeana y de la Patagonia, ver COOPER, J. 1946:127-166, MANDRINI, R., 1991: 309-336 y CASAMIQUELA, R. 1999: 495-534. Sobre la organización de la Campaña al Desierto, ver OLASCOAGA, M, 1881.

4-Un análisis pormenorizado en OTERO, H, 1997-1998: 129-135. 
realizó una eliminación del enemigo en el contexto bélico. En segundo lugar por el desarraigo, ya que muchos indígenas fueron trasladados a prisiones o bien entregados como servidores en casas particulares y no todos se adaptaron con facilidad a ese status inferior. En tercer lugar, porque las enfermedades, sobre todo la viruela, hicieron estragos antes, durante y después de la campaña, hasta tal punto que sus consecuencias formaron parte indiscutible del discurso médico sobre el contagio y la forma de evitarlo.

\section{Etnocidio y enfermedad}

Dentro del discurso ideológico cientificista, la extinción paulatina de los "primitivos" se analizó bajo la óptica de la autoexculpación de los blancos, señalando como directos responsables a los propios indios y a su forma de vida salvaje. La adicción al alcohol, al tabaco y a otros vicios, la suciedad y el nomadismo, el aborto y el infanticidio e incluso la comida eran incumbencia de los indígenas, y frente a esos factores la civilización podía entonces descargarse de cualquier culpa ${ }^{5}$.

La reacción indígena frente a la viruela también fue juzgada como ineficaz, e incluso, a pesar de las fuertes pruebas históricas y médicas en contrario, hubo especialistas que observaron que su mortandad diferencial se debía a aspectos físico-culturales. Desde las primeras épocas de la conquista, la viruela se demostró un "agente" bélico de importancia en la lucha contra los indígenas ${ }^{6}$. En el sur del continente, las primeras epidemias fueron señaladas en el siglo XVIII por fuentes tempranas, que enfatizaron la desesperación de los indígenas ante su aparición y el aislamiento (o abandono) de los enfermos, ante una enfermedad vinculada directamente al contacto con los blancos?.

En el siglo XIX, la existencia de la inoculación variólica y posteriormente la variolización no había eliminado la enfermedad en la población rioplatense, que seguía siendo sacudida periódicamente por epidemias. Los esfuerzos de las autoridades sanitarias por extender la vacunación contra la viruela no tuvieron

5-Como ejemplo, ver URIEN, C.y COLOMBO, E, 1910: 131. También Federico Barbará, oficial de la Campaña al Desierto en 1879, explicaba el fenómeno como de "desaparición" necesaria similar a lo sucedido en el país del Norte (BARBARA, F. 1990: 140) OLASCOAGA (1881: 292), ZEBALLOS, E. (1969: 263) y EBELOT, A (1968: 206) expresaban a finales del XIX iguales argumentos, considerando a los indios verdugos y víctimas a la vez.

6-Con respecto a los efectos de las epidemias en América durante los siglos XVI, XVII y XVIII ver W. MC NEILL, W., 1976 y COOK, N., 1998.

7-AGUIRRE, F., 1949:.340-341 y FALKNER, T., 1954: 181. ROSAS (1947) señalaba que la voz "huinca-cutrán", traducida literalmente como "enfermedad del blanco", significaba "viruela" para los mapuches de las Pampas. 
éxito hasta finales de siglo, cuando comenzó a limitarse la enfermedad en las ciudades más pobladas ${ }^{8}$. La última epidemia de importancia puede citarse en 1886, aunque ya las fuentes señalaban mucho antes una diferencia notable entre el tipo de viruela que afectaba a los indígenas, la viruela confluente, generalmente mortal, y las variedades más leves que afectaban a la población blanca.

Entre 1878 y 1881, la opinión pública porteña se conmovió por la llegada de contingentes indios, por lo que el debate acerca del futuro de la población indígena impregnó diferentes periódicos. Por ejemplo, en el periódico La Pampa un artículo aparecido en agosto de 1879 reclamaba al gobierno nacional la creación de colonias indígenas con los prisioneros, denunciando al mismo tiempo el trato inhumano que éstos sufrían luego de su captura: "Se han hecho aproximadamente 3.000 prisioneros entre indios de lanza y de chusma y es un hecho que de esa cifra no alcanzan 500 los indios destinados a formar colonias, que todavía no se han constituído (...). Los 2.500 restantes, o se han distribuído en los cuerpos de línea o de escuadra, o se han repartido entre las familias, a título de hacer caridad a los indios, como si lo fuese convertirlos en esclavos de quienes los reciben, porque en esa cuenta, a corta diferencia se les tiene, obligándoles a un trabajo constante como peones o sirvientes, que sólo se remunera con algunos desechos de ropa y si acaso con ligeras nociones de intrucción elemental" ${ }^{\prime 9}$.

Estos varones, mujeres y niños, pertenecientes a diferentes etnias de la Pampa y Patagonia capturados luego de la expedición militar de Roca, eran embarcados en el puerto de Carmen de Patagones o por el de Buenos Aires y conducidos a Martín García, lugar utilizado por el Estado como penal. Luego de un período de tiempo variable, de acuerdo fundamentalmente a la cua-

8-La inoculación variólica, práctica popular en Asia Menor y Grecia, se introdujo en Europa a principios del siglo XVIII y de allí pasó a distintos lugares de América. A pesar de que limitaba la aparición de las variantes más graves de viruela (viruela confluente), era peligrosa por sus efectos secundarios y sólo los médicos más avanzados la autorizaban. Se realizaba a partir de la implantación en niños y adultos de costras de personas que hubiesen tenido la "viruela benigna". A finales del siglo XVIII, las investigaciones de Jenner en Gran Bretaña llevaron al uso de la variolización, es decir a la implantación artificial del virus de la viruela vacuna o cow pox, que tuvo una gran expansión en otras partes de Europa. La variolización ha sido definida como el primer gran éxito de la medicina de la Ilustración. La Corona española tuvo especial interés en hacer conocer dicho sistema a través de la Expedición de Francisco Balmis entre 1803 y 1807 a las colonias americanas, que llevaba niños con virus atenuado para vacunar a la población (PESET, J. L., 1973, T. V: 99-103. y LANNING, J. T, 1997: 530-538). En el Río de La Plata, la preocupación por vacunar a un mayor número de personas se puede constatar desde la existencia del Protomedicato, extendiéndose posteriormente a las diversas instituciones sanitarias de los gobiernos independientes.

9-La Pampa, 10-8-1879. 
rentena establecida por las autoridades médicas, la mayoría de las mujeres y niños se repartieron entre las familias porteñas que deseaban acogerlos y el resto fue reunido por sacerdotes salecianos en distintas misiones, incorporados al ejército, como ya lo había sido otro núcleo de indígenas antes de la Campaña o bien retornaron a las tierras otorgadas por el gobierno nacional. Un número importante dejó de existir, víctima sobre todo de la viruela que ya había aparecido como epidemia en los campamentos militares y que los mismos indígenas acarrearon a la prisión isleña y luego a Buenos Aires.

En 1879 se desató una epidemia de viruela en la misma ciudad, que afectó igualmente a la población urbana. La prensa se hizo eco de la preocupación pública, poniendo como principal responsable al gobierno, que podría haber evitado la enfermedad en la ciudad impidiendo la entrada de los indios y dudando al mismo tiempo de ciertas medidas, por ejemplo de la vacunación. La Pampa denunciaba que "...la invasión del mal la debemos al descuido ejercitado por el Ministerio de la Guerra. En efecto, él sabía por telegramas que había recibido de los jefes de la frontera, que la viruela diezmaba a los indios. Esto no obstante, dio orden de que esos indios fuesen remitidos a esta ciudad. Vinieron, fueron distribuidos en las casas de familia y después se produjo lo que era natural que se produjese. Gran número de estos indios, que traían ya desde el desierto el germen del mal, cayeron enfermos, atacados de la peor clase de viruela. El contagio no tardó en producirse y a la fecha los casos se han multiplicado tanto que han puesto en alarma a la población y han determinado a la Municipalidad a lanzar manifiestos incitando a todos a precaverse contra él haciéndose vacunar" ${ }^{\prime \prime 10}$. El periódico no estaba en contra de la vacuna, sino que señalaba la falta de previsión de las autoridades que aún conociendo la situación en la frontera, permitían el ingreso de los contagiados a Buenos Aires. Así proponía que "...lo que debe hacerse es aislar completamente a los indios y a la guarnición de Martín García, como también a la de las fronteras, prohibiendo sobre todo de un modo absoluto que venga de allí un solo indio", llevándoles las medicinas y facultativos necesarios para atacar el mal".

La relación entre epidemia de viruela e ingreso de indios no sólo fue evidente para la prensa, sino también para los especialistas médicos. La tesis del facultativo Baldomero Sommer estaba justamente dedicada a observar detenidamente otra epidemia, la de 1882, vinculada con las expediciones militares. El estudio de Sommer, realizado a partir del análisis de casos de viruela en los hospitales porteños de San Roque y en la Casa de Aislamiento, intenta- 
ba probar que la gran mortalidad indígena de viruela se debía a que éstos contraían el virus en condiciones de baja inmunidad, por lo que éste adquiría un carácter maligno mucho mayor.

La viruela podía presentarse en diferentes formas; las más graves se denominan viruela confluente y hemorrágica y las formas más benignas, viruela discreta. Sommer expresaba en un cuadro estadístico que de un total de 27 indios ingresados con viruela, 20 sufrían la viruela confluente y hemorrágica y sólo 3 la viruela discreta. Los grupos testigo, a los que sistematizaba como "argentinos" por un lado e "italianos" por el otro, contraían más frecuentemente la viruela discreta que las variantes mortales ${ }^{12}$.

Basándose en los aportes de Pasteur sobre la atenuación de los virus a partir de la vacunación, Sommer especulaba que entre los indios podría haberse producido un efecto contrario. Para el médico, el contagio de los indígenas se había realizado durante su traslado desde las tolderías, al pasar por los poblados blancos. El virus variólico había ingresado en el organismo de los nativos y al no estar vacunados, revestía mayor malignidad, o como también expresaron otros médicos, la viruela hallaba un "terreno fértil y virgen"13 donde desarrollarse.

José Penna y Pedro Mallo, ambos médicos, intentaron también dar una respuesta al interrogante planteado sobre las formas diferentes que asumía la enfermedad entre blancos e indios. Penna expresaba en una obra general escrita en 1885 que "...un estudio bien detenido de la viruela y de la vacuna, fundado en la observación y en la experiencia de lo que pasa en nuestro país, nos lleva a mirar la pureza de la raza, en la pureza de la sangre, en una palabra, en la ausencia de todo cruzamiento, como ha sucedido hasta hace poco con los indígenas de América, una de las causas esenciales de su susceptibilidad para la viruela y la fecundidad, si así puede decirse, con que en ellos se desarrolla. Por eso la gravedad es tan grande en tales casos ${ }^{\prime \prime 14}$. Este facultativo era entonces uno de los partidarios de explicar el efecto diferencial de la enfermedad, mencionando una cuestión que se acerca en parte a las teorías actuales, relacionada con cierta predisposición genética a la viruela en aquellos grupos étnicos que han sufrido un aislamiento prolongado.

La mayor susceptibilidad de los amerindios a las enfermedades epidémicas como tifus, fiebre amarilla, sarampión, varicela, cólera y viruela ha sido explicada a partir de diferentes tesis que analizan por qué no se produjo la misma 
inmunidad vírica y bactereológica que existía en las poblaciones europeas y africanas. La "pantalla del frío", que acompañó a los migrantes desde Siberia al norte de América hizo imposible que determinados patógenos y sus huéspedes (insectos, por ejemplo) pudieran generarse. La falta de animales domésticos, que también son un depósito horizontal de enfermedades, pudo consolidar esta falta de microorganismos, así como la baja tasa poblacional de las poblaciones migrantes desde Asia, que impidió mantener un determinado número de patógenos como para que se conformaran endemismos y en consecuencia hubiese personas con un potencial genético inmune a los mismos ${ }^{15}$.

En el siglo XIX, aunque las teorías sobre la herencia de determinados caracteres no estuviesen desarrolladas, diferentes especialistas consideraban que ciertas enfermedades eran más proclives entre un conjunto humano que en otro y que otras se transmitían de generación en generación. Esta cuestión dio origen a la geografía médica por un lado y al estudio de la constitución de las "razas" humanas por el otro, para distinguir los particularismos que permitían la presencia/ausencia de enfermedades. José Penna fue uno de los médicos que intentó avanzar en su estudio monográfico referido a la viruela sobre estas cuestiones, demostrando en cierta medida una rara cualidad empírica al despojarse de los prejuicios que circulaban sobre la viruela entre los indígenas.

Penna citaba casos producidos en las mismas instituciones de Sommer, como la Casa de Aislamiento, y en el mismo período de tiempo, explicando que la estadística demostraba que dos tercios de los indios ingresados fallecían. Este facultativo decía que las causas que se habían mencionado, como sus hábitos antihigiénicos y la ignorancia y brutalidad de sus prácticas empíricas o incluso una piel más permeable a las infecciones carecían de base sólida, porque el indio como organización material, como fuerza viva y por su resistencia, "...es al fin un hombre, bárbaro si se quiere, pero bajo el punto de vista físico, capaz como ningún otro de soportar las dolencias físicas también y las enfermedades destructoras"16. La afirmación antropológica de Penna es asombrosa fundamentalmente porque constituía la base de su argumento médico, para así despejar el camino y analizar científicamente la cuestión.

El texto de Pedro Mallo, escrito hacia 1898, testimoniaba la persistencia de creencias opuestas dentro de la comunidad científica, defendidas no por un sector marginal sino por uno de los más brillantes higienistas, profesor de la Facultad de Medicina y reconocido profesional. Partiendo de la afirmación de que "...las viruelas facilitaron la conquista del continente americano, porque 
arrasó pueblos enteros y llegó a inspirar más terror a los naturales que las armas de fuego" ${ }^{\prime 17}$, Pedro Mallo explicaba sin embargo el carácter mortífero de las epidemias por la falta de aseo de los nativos "...su desnudez, robustez y poca facilidad para transpirar y más que todo, una inexplicable predisposición a contraer la enfermedad, que siempre revestía carácter grave (así como) la falta de medidas de desinfección"18.

La "inexplicable" predisposición era considerada en forma superficial y aunque Mallo conocía de hecho la teoría microbiana y la base teórica que sustentaba la vacunación, no hizo aparentemente esfuerzos para reflexionar sobre otras posibilidades. A pesar de citar profusamente fuentes históricas sobre el impacto de la viruela desde el siglo XV en América, la culpa recaía sobre los indios, quienes conscientemente, es decir, por sus costumbres y formas de vida o bien inconscientemente, a partir de sus diferencias biológicas, demostraban ante la civilización una incapacidad total para hacer frente a la enfermedad.

A diferencia de Mallo, Penna planteaba que las diferencias entre la virulencia variólica de blancos e indios se debían fundamentalmente al conocimiento y uso de la vacuna y no a otra causa. La variolización, a pesar de ser una técnica implantada tempranamente en Argentina, ocasionaba fuerte resistencia entre la población blanca. Su eficacia, sin embargo, se acrecentó a lo largo del siglo así como la certeza entre los profesionales sanitarios de que era necesario vacunar para eliminar esta epidemia ${ }^{19}$. Penna explicaba que los pueblos indígenas nunca habían sido vacunados y tampoco se habían mestizado con otros vacunados o inoculados a diferencia de los pueblos civilizados: "...La experiencia en las grandes epidemias demuestra la atenuación real que el mal variólico sufría al invadir poblaciones inoculadas o vacunadas" ${ }^{\prime 20}$.

Tal como había sido planteado por la prensa, Penna y Sommer se sorprendían que los prisioneros no hubiesen sido vacunados en forma masiva antes de ser trasladados. Según Sommer porque "..traer las tribus conquistadas a la ciudad de Buenos Aires, sin haberlas vacunado previamente, es un defecto inconcebible y un error imperdonable ${ }^{\prime \prime 21}$. Por los informes de Olascoaga se sabe sin embargo que los capturados por la III División fueron vacunados y

17-MALLO, P., 1898, II: 12.

18-MALLO, P., 1898, II: 66.

19-Desde 1872, una Ley provincial obligaba a médicos y padres de familia a denunciar ante el Consejo de Higiene, organismo sanitario provincial, o a la Sección de Higiene de la Municipalidad de Buenos Aires los casos de enfermedades epidémicas, entre las que se contaba la viruela. Recién en 1886 se aprobó la Ley Nacional de Vacunación Obligatoria, encaminada sobre todo a luchar contra la viruela (CONI, E., 1887: 27 y 214).

20-PENNA, J., 1885: 93.

21-SOMMER, B, 1884: 13. 
según José Penna, también en Carmen de Patagones se vacunó a la población indígena luego de la Expedición al Río Negro, en el año $1881^{22}$. Sommer como Penna daban fe que, una vez vacunados, los prisioneros podían desarrollar la viruela pero en sus variantes leves, según los casos que habían podido observar. Ambos coincidían en adjetivar la viruela entre los indios como "cruel y fecunda" y la imagen que surge es la un indio-tierra donde el mal se desarroIla como un vegetal perverso y dañino, eliminando a su vez al huésped. Frente a tal situación, proponían vacunar a los indios, ya que éste era el único preservativo eficaz que permitiría el control de la enfermedad entre las etnias pampeanas, parte integrante a partir de ese momento de la población nacional.

Los datos parciales citados afirmarían la idea de que los jefes militares eran conscientes de la eficacia de la vacuna, suficientemente probada entre la población blanca. De hecho, algunos de ellos vacunaron por propia decisión o por consejo médico a los recluídos en los campamentos militares. Los informes médicos aceptaban la inmunidad que otorgaba la vacuna, sobre todo a partir de la extensión de los estudios epidemiológicos de la segunda mitad del XIX. Sin embargo, muchos indios no fueron vacunados, con lo cual no sólo se introdujo peligrosamente un foco de contagio sino que fue una forma indirecta de asegurar su desaparición, bajo un arma que era a la vez terriblemente eficaz y desculpabilizante. En las palabras de Pedro Mallo, se produjo una lamentable "devastación accidental", en la cual los blancos no necesitaban asumir su responsabilidad.

\section{Almas que salvar. La Iglesia frente a la viruela}

Como se ha señalado, la mayoría de los indígenas capturados durante la campaña militar estaban enfermos de viruela, lo cual se hizo evidente en los primeros meses de su prisión, cuando fue necesario habilitar en Martín García un lazareto para cuidar de ellos. El arzobispado de Buenos Aires tomó inmediatamente cartas en el asunto, ocupándose de enviar hermanas de caridad y sacerdotes, como el padre Birot, para hacerse cargo del mismo.

Aneiros se había interesado por la evangelización indígena desde hacía varios años y antes de él, los franciscanos del Colegio Apostólico de Propaganda Fide de Río Cuarto en Córdoba. Entre 1870 y 1872 varios franciscanos, tanto acompañando a misiones diplomáticas como mandados directamente por el Estado, realizaron acuerdos con los indígenas ranqueles y aprovecharon para 
bautizar indígenas ${ }^{23}$. En 1872, el arzobispo fundó el Consejo para las Misiones del Indio y en los años subsiguientes, organizó la misión a Azul, donde envió al padre Meister, el viaje a Salinas Grandes con el padre Salvaire y la misión de Bragado, llevada a cabo también por el padre Salvaire y el padre Sabino.

El padre Salvaire, perteneciente a la congregación de San Vicente de Paul, escribió a finales de siglo el relato de sus experiencias misionales frente a los indios. En 1873 se entrevistó con el cacique Catriel en Azul y con el cacique Railef en Bragado; en 1874 estuvo en General Viamonte con la tribu de Coliqueo y en 1875 el gobierno de Alsina solicitó su mediación para rescatar cautivos y realizar acuerdos con el cacique Namuncurá en Salinas Grandes. En ese año las relaciones entre indios y blancos atravesaban un momento crítico y la intermediación de Salvaire estuvo a punto de fracasar cuando fue acusado primero ante Namuncurá y luego ante Railef de llevar el walicho ${ }^{24}$. El sacerdote atribuyó a la Virgen su salvación en ese instante, cuando peligraba su vida y prometió contruirle un santuario, lo que posteriormente realizó dando lugar a la enorme basílica de Luján, una de las sedes de peregrinación más concurridas de todo el país.

A diferencia de lo ocurrido en las tolderías bonaerenses de Azul y Bragado, Salvaire no pudo formalizar una misión en Salinas Grandes ya que Namuncurá se lo impidió, pero sí logró llevar consigo a su sobrino, Amaro, para educarlo en Luján. En 1884, cuando Namuncurá fue vencido totalmente en Neuquén luego de ser acorralado cerca de la cordillera por las tropas nacionales, fue posible establecer una misión en Chimpay, sobre el Río Negro, con los restos de su tribu en la que destacó Ceferino, hijo del cacique Namuncurá, conocido luego de su muerte como "el santito indio" y "el lirio de las Pampas"25.

Ahora bien, la organización de misiones indias estaba dentro de la lógica del gobierno nacional, ya que aunque fuera laico y liberal, carecía de una estructura educativa lo suficientemente eficaz como para "pacificar" y aculturar a grandes conjuntos étnicos fuera de las ciudades y aún en las del interior,

23-En 1870, un franciscano acompañaba a Mansilla a firmar la paz con los caciques Mariano Rosas y Baigorrita y en 1872, dos sacerdotes del colegio cordobés fueron enviados por Sarmiento a mantener los acuerdos (BRUNO, C., 1993: 623).

24-HUX, M., 1979: 75 y 125. Walicho refiere en mapu-dungun, idioma mapuche que en general era hablado por los indígenas pampeanos, al "daño", es decir, a la mala suerte, muerte o enfermedad (FOERSTER, R., 1993).

25-COLUCCIO, F.(1984: 94). Ceferino murió en Roma y actualmente está en proceso de beatificación en la Santa Sede en relación a milagros curativos. Todavía hoy sigue siendo objeto de culto en diversos santuarios levantados a la vera de caminos en las provincias de Buenos Aires, Neuquén y La Pampa, donde se le elevan peticiones como ejemplo de pureza y abnegación cristiana. 
la tarea educativa era dificultosa. Pero en general, el trabajo misional se produjo luego de la campaña militar ${ }^{26}$, cuando las autoridades estuvieron seguras de que ya no era posible que los indígenas se reorganizaran en confederaciones (como las reunidas en los '50 por Calfucurá y Sayhueque y hacia 1872 por Namuncurá), haciendo peligrar los bienes y territorios blancos con malones y captura de ganado y cautivos. La aculturación progresiva de los sobrevivientes fue una estrategia destinada a impedir el resurgimiento del poderío de ranqueles, pehuenches y tehuelches en la Pampa y la Patagonia y en ese esquema, la acción educadora de la Iglesia era fundamental.

Pero en otras cuestiones, el Estado y la Iglesia no estaban totalmente de acuerdo, ya que ambas instituciones pugnaban por mantener -la Iglesia- o acrecentar -el Estado- el control demográfico y social. El conflicto puede evidenciarse durante los gobiernos de Roca y Juárez Celman en el establecimiento de la Ley de Registro Civil, que obligaba a la población a inscribir en instituciones estatales los nacimientos, matrimonios y defunciones, y la Ley de Enseñanza, que establecía en todo el país la educación obligatoria, libre y laica. La denominada generación del ' 80 coincidía en mantener un ideario liberal y anticlerical y era contraria al intervencionismo religioso en los asuntos estatales, sobre todo porque contradecía el espíritu constitucional de apertura hacia el exterior y a la vez era un freno a determinadas acciones gubernamentales ${ }^{27}$.

Parte de ese debate se desgrana en los artículos de La América del Sur, el diario católico dirigido por Santiago Estrada ${ }^{28}$, en relación con la acción religiosa en Martín García frente a las epidemias de viruela. En enero de 1879, aparecieron casi diariamente menciones a la gran mortalidad de los indios, sobre todo de niños, que al haber sido concentrados en un presidio se exponían al frío y al hambre. Todos carecían de vestidos, estaban cubiertos por harapos, sin comida ni utensilios. La respuesta caritativa no se hizo esperar: en febrero se publicó una noticia donde el arzobispo y las hermanas de caridad de San Vicente de Paul, junto con las damas de beneficiencia ${ }^{29}$, habían recolectado mantas y ropas para enviar a Martín García.

26-Hubo dos intentos entre 1873 y 1874 apoyados por Julio A. Roca, cuando era todavía coronel de fronteras, pero estas misiones en Villa Mercedes (San Luis) y cerca de Río Cuarto no llegaron a ser permanentes (BRUNO, C., 1993: 624).

27-Un desarrollo completo del problema en IVEREIGH, A.,1995: 49-72.

28-Según BRUNO, la fundación de este periódico católico obedeció al impulso de monseñor Aneiros, quien desde 1875 se preocupaba por la abundancia de publicaciones porteñas "impías y antirreligiosas" (1993: 594).

29-La Sociedad de San Vicente de Paul era una institución laica, pero "bendecida y auxiliada por la religión". A ella pertenecían también algunos religiosos, tanto padres como hermanas. Tal como otras asociaciones de beneficiencia, recibía aportes de las familias más encumbradas, como los Paz y Anchorena e 
El tono de denuncia de los artículos se evidencia al referir no sólo las malas condiciones generales de los indios concentrados en la prisión sino la imprevisión de las autoridades en materia sanitaria:"...Creemos hacer un servicio a los indígenas del lazareto de variolosos publicando estas líneas, y al gobierno de la nación para que averigüe que hay de cierto. Los males deben corregirse y no es extraño que habiendo sido conducidos los indígenas de una manera inopinada, hayan ocurrido necesidades no previstas". Asimismo, se hacían constar las gestiones del arzobispo frente al gobierno para remediar los problemas de los "...desgraciados, de acuerdo a leyes de humanidad"30.

En realidad la tarea de los lazaristas religiosos se complicaba sobremanera en el presidio y el número de muertos no cesaba de aumentar, sobre todo frente a la inexistencia de médicos ante la renuncia del facultativo encargado, Telémaco Susini. El periódico católico reproducía en sus páginas una polémica con El Siglo, donde este último expresaba que ante la magnitud que asumía la epidemia de viruela entre los indios, la Iglesia se había limitado sólo a bautizarlos, negándoles cualquier otra asistencia. La América del Sur, por su parte, relataba ampliamente la ayuda dada a los indios, afirmando además que los sacerdotes y hermanas de caridad brindaban los auxilios del alma junto con los del cuerpo. Así, reproducía un listado donde certificaba el bautismo de 358 y la muerte de 71 indígenas en febrero de 1879.

El debate entre las dos publicaciones se mantuvo los días subsiguientes: El Siglo estaba en desacuerdo con el sacramento bautismal mientras que los católicos lo defendían como una forma de registro de la población que a la vez permitía su integración inmediata a la nación. Si no se bautizaran, el Estado debería utilizar métodos inciertos para conocer quiénes eran e inscribirlos en el registro civil. El uso de lenguaraces y de funcionarios bilingües le parecía al corresponsal de La América del Sur totalmente irrealizable; y por lo tanto proponía en su lugar bautizar a los indios, darles nombre cristiano y reputarlos como recién nacidos, porque eso eran para la Iglesia ${ }^{31}$.

El pasado étnico quedaba así borrado para siempre y el antiguo indio era escondido bajo la apariencia de un habitante argentino; su nombre desaparecía y con él la forma de asumir una identidad indígena. Esta metodología no era nueva en absoluto, ya que la Iglesia la había aplicado durante siglos en otros

intervenían en su organización damas de la oligarquía porteña, como Constanza Ramos Mexía de Bunge y Carmen O'Gorman. En 1873, las Damas de San Vicente de Paul habían fundado asilos maternales en Buenos Aires y mantenían también otras instituciones para enfermos y pobres (MEYER ARANA, A., 1911, T. II: 17 y 140).

30-La América del Sur, 27-2-1879.

31-La América del Sur, 4-3-1879 y 5-3-1879. 
territorios americanos, pero al mantenerse el sistema de castas colonial, las personas siguieron utilizando una denominación étnica aunque no de manera mecánica ni la misma durante toda la vida. En el caso argentino, quedan explicados un número importante de indios "desaparecidos" luego de la campaña militar, ya que al ser bautizados se les imponía un nombre cristiano y los recuentos censales posteriores los consideraban dentro de la categoría genérica de población argentina nativa.

La discusión sobre bautismo-no bautismo de los indios asumió en los números posteriores una controversia entre la validez del registro civil y el control estatal y el mantenimiento de los registros bautismales católicos ${ }^{32}$. En 1878, el periódico cristiano explicaba que para la Iglesia el problema era establecer a qué edad era conveniente bautizar sin dar instrucción religiosa. Se concluía que los niños indios podían ser bautizados hasta los siete u ocho años de edad sin tenerla, pero los mayores requerían ya cierto tipo de enseñanza ${ }^{33}$. Sin lugar a dudas, los variolosos y las criaturas pequeñas debían ser cristianizados para salvar sus almas en peligro de condena eterna.

Ahora bien, a finales de marzo y principios de abril, se señalaba que la epidemia de viruela ya había sido controlada y se daban partes periódicos de indígenas muertos y bautizados. Por ejemplo, el día 20 de marzo se registraban 150 muertos y 500 bautizados y según el periódico del 3 de abril, había 207 fallecidos y 537 bautizados, sin que se aclarara si estos últimos estaban incluídos en la cifra anterior. Antes y después de la epidemia, los indios se estaban distribuyendo entre las familias bonaerenses y aunque habían pasado por una cuarentena, algunos podían estar contagiados de viruela. En varias oportunidades, se denunció además un sistema de esclavitud encubierta llevado a cabo tanto por la Sociedad de Beneficiencia, que era la institución que repartía los prisioneros, como por aquellos encargados finalmente de los indios, que podían separar padres de hijos y explotar a todos servilmente ${ }^{34}$.

Para las autoridades católicas el problema principal, según se evidencia de la lectura del periódico, era evitar que los indios encomendados a familias fuesen bautizados otra vez, por lo que se publicaron en diferentes fechas listados de indígenas cristianizados. La América del Sur señalaba que el sacramento y la instrucción les permitiría realmente a los indios repartidos emanciparse de la tutela de los blancos y a la vez integrarse a la sociedad nacional como ciudadanos. "No queremos en la República Argentina bárbaros ni esclavos", decía

32-La América del Sur, 5-3-1879, 7-3-1879 y 20-3-1879..

33-La América del Sur, 2-8-1878.

34-La América del Sur, 1-2-1879 y La Pampa, 10-8-1879. 
el diario católico, para continuar con la idea de que la evangelización permitiría hacer penetrar la civilización a todos los niveles luego de la conquista al desierto, evitando los crímenes que se perpetraban en la Pampa cuando se carecía del conocimiento cristiano ${ }^{35}$.

Esta preocupación que parece ser cívica, ya que hay una clara referencia a la asimilación política del indígena como "ciudadano", tiene un correlato más profundo, porque en realidad el periódico planteaba la oposición en los viejos términos de cristianos/no cristianos. Pero ya a finales del siglo XIX, ese dualismo tradicional había sido sustituído en forma lenta, en una sociedad progresivamente laica e influenciada por el positivismo, por el de civilizados/no civilizados, dificultándose la identificación entre no cristianos-no civilizados. Por lo tanto, ya fuese para las autoridades estatales como para una mayoría de los sectores elitarios, la evangelización no podía ser ya la solución total a los problemas con los indígenas y no se podía confiar absolutamente a la Iglesia los indios prisioneros.

De hecho, tanto las autoridades militares como civiles habían mantenido respecto a la política indígena y la Iglesia una actitud un tanto vacilante, sin llegar a oponerse verdaderamente a la injerencia del arzobispo y de los lazaristas en Martín García, pero a la vez sin apoyar tampoco los proyectos arzobispales de establecer reducciones indígenas donde el Estado no tuviese intervención. Sin duda, en una etapa marcada por el centralismo estatal, era lógico que no se permitiera aumentar el control religioso a un sector nuevo, del que la Iglesia carecía con anterioridad a la Conquista al Desierto. Esta situación puede observarse en concreto cuando fracasó el plan original de Aneiros de formar colonias indígenas separadas completamente del contacto con los "malos cristianos", y además, cuando el Consejo de las Misiones hubo de recibir a inspectores estatales para supervisar la tarea religiosa ${ }^{36}$.

La insistencia evangélica puesta en el bautismo se evidenció también posteriormente, cuando los salecianos iniciaron su tarea expansiva en la Pampa y sobre todo la Patagonia argentina. Aneiros mismo se había entrevistado en Italia en 1879 con Juan Bosco y le había solicitado el envío de sacerdotes y monjas para evangelizar a los indios, los cuales se ubicaron en primer lugar en Carmen de Patagones y Viedma y luego en el resto de la Patagonia ${ }^{37}$. La América del Sur expresaba que los misioneros se habían establecido temporalmente en los ríos 
Negro y Colorado, bautizando más de 1.200 indios, sobre todo porque entre ellos había estallado una epidemia de viruela que provocaba gran mortandad. Gracias al bautismo, los indígenas "...forman parte de un pueblo culto y civilizado. En adelante, no se mirará en ellos a seres abyectos y degradados por el vicio y la ignorancia, sino por almas ennoblecidas y regeneradas" ${ }^{\prime \prime 38}$.

El punto esencial fue precisamente que los indios eran "almas" para los misioneros y consecuentemente como tales debían ser acercados a la salvación. Los cuerpos "despreciables" de los indígenas se transformaron en espíritus que podían "robarse" el paraíso solamente con la conversión al catolicismo antes de morir. La tarea de suministrar el sacramento cristiano a los condenados por la viruela no es percibida, ni se desea dar a entender eso en este texto, como un acto inútil, sino como una acción fundamental plena de dedicación a los demás, de sacrificio y caridad. Tanto el periódico católico como las palabras de Aneiros y de los misioneros expresaban esa convicción profundamente arraigada, que sin embargo a finales del XIX ya no recibía igual aceptación en toda la sociedad.

En consecuencia, el pastor-misionero que cuidaba de sus ovejas-indios y a quien le preocupaba mucho más que el bienestar físico de las mismas la administración sacramental, recibió críticas desde varios sectores, entre ellos de aquellos liberales que tampoco se ocupaban demasiado de los indios, pero para quienes la Iglesia representaba un peligro latente.

El Siglo, por ejemplo, culpabilizaba a los lazaristas de las muertes de viruela en Martín García, ya que los sacerdotes no se ocupaban más que dar los auxilios del alma a los indígenas. Por otra parte, el malestar entre ambos sectores se evidenció también en los reparos señalados por los católicos: La América del Sur criticaba a las autoridades, sobre todo sanitarias, al establecer que sólo los religiosos se ocupaban de los indios, abandonados de todo cuidado por el Estado. En 1880, cuando aparecieron nuevamente epidemias entre los indios, La América del Sur reprodujo las objeciones de los misioneros, quienes expresaban que ellos nada podían hacer y que "...El Gobierno debe enviar algún facultativo a fin de evitar en lo posible la propagación del mal. ¿Qué harán los indios sin recursos de ningún género?"39.

En este cruce de opiniones entre las responsabilidades del Estado, los médicos y la Iglesia estaban los indios, pero ellos ya no se encontraban en posición de negociar con unos y otros. Definitivamente, habían dejado de ser cuerpos, pero cuerpos reales, para convertirse en puro espíritu y es sabido que éstos 
carecen de voz y mucho más de voto u opinión.

\section{Reflexiones finales}

Las circunstancias especiales que rodearon la Campaña al Desierto, provocando un descenso acusado de la población nativa, fueron entrevistas por una serie de médicos, políticos, militares, periodistas y eclesiásticos-misioneros de forma diferente. En principio, una de las causales más importantes fueron las epidemias de viruela, que influían mortíferamente entre los indios y que llevaron a reflexionar sobre las diferencias biológicas, esbozándose así teorías sobre el aislamiento racial y la herencia de caracteres físicos, cercanas en cierta medida a las explicaciones actuales sobre la acción epidémica. Por otra parte, también se desarrollaron entre diversos intelectuales; posturas que culpabilizaban del etnocidio a los mismos indígenas, incapaces de desarrollar adecuadamente los cuidados higiénicos o bien, inferiores físicamente a la civilización occidental, que podía hacer frente con mayor éxito a la viruela.

Estas últimas reflexiones teóricas, propias del positivismo reinante en los círculos intelectuales argentinos, acompañaron indefectiblemente la tarea de los funcionarios gubernamentales y de ciertos militares en los movimientos efectuados antes, durante y después de la Campaña, en la medida que la viruela fue percibida como un eficaz arma biológica. Sin embargo, estas consideraciones no se generalizaron a toda la población, ni siquiera en todos los círculos académicos o de decisión político-militar, donde pueden encontrarse variantes significativas. El estudio de indígenas variolosos en un hospital para demostrar la necesidad de la vacuna, las protestas de la prensa a la deficiente organización del reparto de indígenas en la ciudad, e incluso, la vacunación de indígenas prisioneros, señalaría la existencia de opiniones contrarias o al menos diferentes. El hecho de que se tratase de posturas de una minoría no invalida su valor, e implica una ineludible profundización en la historia de las relaciones entre blancos e indios, sobre todo en la vertiente de las ideas científicas, para evitar generalizaciones superficiales.

Con respecto al otro punto analizado en este artículo, resulta interesante observar la forma que asume el conflicto entre la Iglesia y el Estado argentino, en parte a través de la prensa, en relación con la integración de la población indígena. Las epidemias de viruela en un presidio son de alguna manera pretexto de confrontación entre la defensa del establecimiento de un control laico y gubernamental más preciso, frente al interés eclesiástico por incrementar la injerencia ideológico-política a otros conjuntos sociales, supuestamente más 
débiles y necesarios de atención.

Unos y otros, Estado e Iglesia, proponían que la incorporación luego de la Campaña y de las epidemias subsiguientes significase un "nuevo nacimiento" para los supervivientes. Tanto el bautismo como la inscripción en el Registro Civil superponían la pérdida de la identidad étnica a la desaparición de la vida comunitaria, los lazos parentales, la vinculación territorial y obviamente, la lengua y la religión. La enfermedad con su secuela mortífera fue el correlato final de la mayoría de la población indígena; díficil de establecer en toda su magnitud, pero a la cual sólo le quedaba el robo del paraíso.

\section{Resúmen}

\section{Robar el paraíso. Indios, viruela y bautismo en Argentina (1870-1884)}

EI presente artículo analiza el debate sobre la incorporación de los indígenas al conjunto nacional a partir de una epidemia de viruela en la década del ' 80 en la ciudad de Buenos Aires. Dicha epidemia se produjo a raíz del ingreso masivo de prisioneros nativos como consecuencia de la campaña militar realizada en 1879 en la región pampeana. En la discusión sobre contagio y vacunación intervienen diversos actores sociales, como la Iglesia, médicos y militares, así como la prensa tanto liberal como católica. En el fondo, se trata de una controversia entre la salvación de las almas o el cuidado corporal, cuestión de importancia fundamental tanto para el discurso religioso como médico de finales del siglo XIX.

\section{Palabras claves}

- Indígenas - Argentina - Epidemia - Contagio -

\section{Abstract}

\section{Steal Paradise. Indians, smallpox and baptism in Argentina (1870-1884)}

This paper analizes the debate concerning the inclusion of indians into national society, startig from a smallpox epidemics occurred in the $80 \square$ s at Buenos Aires city. Such epidemics was caused by the massive coming of native prisoners, as a consequence of the military campaign that had been made in 1879 in the pampas region. Diverse social actors, such as the Church, doctors and members of the army, as well as both the catholic and the liberal press, took part in the debate on contagion and vaccination. Actually, it is a controversy between soul salvation or body care, an extremely 
important issue for both religious and medical discourse in the late XIX century.

Key words

- indians - Argentina - epidemics - Contagion -

\section{Referencias Bibliograficas}

*AGUIRRE, Francisco (1949) "Diario del Capitán de Fragata Don Juan Francisco de Aguirre". En: Revista de la Biblioteca Nacional, Buenos Aires, Imprenta de Educación, T. XVIII.

*BARBARÁ, Federico (1990) Manual de la lengua pampa, Buenos Aires, Publicaciones de la Junta Histórica de Cultura Argentina.

*BRUNO, Cayetano (1993) La iglesia en la Argentina. Cuatrocientos años de historia, Buenos Aires, Centro Saleciano de Estudios "San Juan Bosco".

*CASAMIQUELA, R., (1999) "Los pueblos del Extremo Austral del continente (Argentina y Chile)", en: T. Rojas Rabiela, dir., Historia general de América Latina I, Las sociedades originarias, París, Trotta-Unesco, p. 495-534.

*COLUCCIO, Félix (1984) Diccionario de creencias y supersticiones (argentinas y americanas), Buenos Aires, Corregidor.

*CONI, Emilio (1887) Progrès de l'hygiène dans la Republique Argentine, Paris, Libraire J. B. Baillière et fils.

*COOK, Noble (1998) Born to die. Disease and New Word conquest, 14921650, Cambridge, University Press.

*COOPER, J (1946) “The Patagonian and Pampean Hunters”, en: J. Steward, ed., Handbook of South American Indians, Vol. I, The Marginal Tribes, Washington, Smithsonian Institution, p. 127-166.

*COPELLO, Luis (1945) Gestiones del Arzobispo Aneiros a favor de los indios hasta la Conquista al Desierto, Buenos Aires, Imprenta Coni.

*CRAWFORD, Michel (1992) Antropología biológica de los indios americanos, Madrid, Mapfre.

*EBELOT, Alfred (1968) Relatos de frontera, Buenos Aires, Solar-Hachette.

*FALKNER, T. (1954) Descripción de la Patagonia y de las partes adyacentes de La América del Sur, Buenos Aires, Solar-Hachette.

*FOERSTER, Rolf (1993) Introducción a la religiosidad mapuche, Santiago, Editorial Universitaria.

*HUX, Meinrado (1979) Una excursión apostólica del Padre Salvaire a Salinas Grandes, Buenos Aires, Ediciones Culturales Argentinas.

*IVEREIGH, Arthur (1995) Catholicism and Politics in Argentina, 1810-1960, 
Oxford, Saint Martin Press.

*LA AMÉRICA DEL SUR (1878-1880).

*LA PAMPA, Diario de la mañana (1879-1882).

*LANNING, John T. (1997) El Real Protomedicato. La reglamentación de la profesión médica en el Imperio español, México, UNAM.

*MALLO, Pedro (1898) Páginas de la historia de la medicina en el Río de la Plata. Apuntes históricos sobre viruela, variolización y vacuna, Buenos Aires, Imprenta Real A. Itter, T. I y II.

*MANDRINI, Raúl (1991) "La sociedad indígena de las Pampas del siglo XIX", M. Lischetti, ed., Antropología, Buenos Aires, Eudeba, p. 309-336.

*MC NEILL, William (1976) Plagues and peoples, Anchor Press, New York. *MEYER ARANA, Alfredo (1911) La caridad en Buenos Aires, Barcelona, Sopena, T. I y II.

*NICOLETTI, María A. (1999) “La organización del espacio patagónico: La Iglesia y los planes de evangelización en la Patagonia desde fines del siglo XIX hasta mediados del siglo XX". En: Quinto Sol, Revista de Historia Regional, Santa Rosa, FCH, Instituto de Historia Regional, año 3, nº 3, p. 29-52.

* OLAscoAgA, Manuel (1881) La conquête de la Pampa. Recueil de documents relatifs a la campagne du Rio Negro, Buenos Aires, Imprimerie du Courier de la Plata.

*OTERO, Hernán (1997-1998) "Estadística censal y construcción de la nación. El caso Argentino, 1869-1914”. En: Boletín del Instituto de Historia Argentina y Americana “Dr. Emilio Ravignani”, Tercera Serie, n 16 y 17.

*PENNA, José (1885) La viruela en la América del Sud y principalmente en la República Argentina. Historia, estadística, clínica y profilaxia. Buenos Aires, Félix Lajuane ed.

*PESET, José L. (1973) "Terapéutica y medicina preventiva". En: P. Laín Entralgo, dir. Historia Universal de la medicina, Barcelona, Salvat, T. V, p. 99103.

*PRIMER CENSO NACIONAL (1872) 15-17 de setiembre de 1869. Buenos Aires, Imprenta El Porvenir.

*ROSAS, Juan M. (1947) Gramática y diccionario de la lengua pampa, Buenos Aires, Albatros.

*SEGUNDO CENSO DE LA REPÚBLICA ARGENTINA (1898), mayo 10 de 1895, Buenos Aires, Taller Tipográfico de la Penitenciaría Nacional, T. I y II.

*SOMMER, Bartolomé (1884) Contribución al estudio de una epidemia de viruela, Tesis de Doctorado, Buenos Aires, Imprenta La Pampa.

*TERCER CENSO NACIONAL (1916), 1 de junio de 1914. Buenos Aires, Talleres Gráficos de L. J. Rosso y Cía, T. I a X. 
*URIEN, Carlos y COLOMBO, Ecio (1910) La República Argentina en 1910, Buenos Aires, Editorial Casa Maucci.

*ZEBALLOS, Estanislao (1969) Viaje al país de los araucanos, Buenos Aires, Hachette. 